and purifying it to hecogenin acetate. Production and marketing of the chick sexer and aural microscope are proceeding satisfactorily.

Of the 664 inventions communicated to the Cor poration during the year, 268 were from government departments and research councils, 50 from Common. wealth official organizations, 18 from industrial research associations, 38 from universities and 269 from British firms and individuals. The rights of 375 patents and patent applications were assigned to the Corporation during the year, of which 315 were from government departments and research councils, 14 from industrial research associations, 30 from universities and 8 from British firms and individuals. The Corporation now holds some 2,647 United Kingdom and overseas patents and patent applications, and, of the 272 licence agreements with industry in force, 99 were revenue-earning, producing $£ 27,650$ during the year.

\section{CENTRAL LABORATORIES FOR SCIENTIFIC AND INDUSTRIAL RESEARCH, HYDERABAD \\ REPORT FOR 1953}

$\mathrm{T}$

HE annual report* for 1953 of the Central Laboratories for Scientific and Industrial Research, Hyderabad, stresses the increasing number of postgraduate students - twenty-two were working in the Laboratories for their Ph.D. in 1953-as evidence of the increasing concribution of the Laboratories both in training and in scientific and technical research. The research staff now numbers fifty-eight, and the report lists twenty-five papers published during the year, apart from forty communicated to the forty-first Indian Science Congress, held at Hyderabad in 1954.

In the Oils Section of the Laboratories, work was carried out on local bleaching earths, and on the preparation of dehydrated castor oil giving completely tack-free films and of alkyd resins modified by castor oil. The solubility and effectiveness of aca-catechin and katha-catechin as antioxidants in ghee were studied, the separation of fatty acid mixtures by adduct formation with urea was shown to be a much simpler method than conventional methods, and a suitable method was worked out for refining cotton-seed oil on a cottage-industry basis. The Entomology Section continued its studies of the toxicity of the seed oil from Annona squamosa (sitaphal) to vertebrates, and this oil appears to be fungistatic rather than fungicidal to Helminthosporium (paddy). The Paper Section was placed on a semi-commercial scale, and good progress was made in the manufacture of drawing paper and bond paper. In the Fuel Section the erection of the 12 ton/day ovoid briquetting plant was completed and the plant put into operation; experiments on binders for low-temperature tar continued. Further work was carried out on the distillation of lowtemperature tar, the solvent extraction of tar acids and hydrocarbons from coal tar oils, and on benzole recovery from the low-temperature carbonization gas, while a systematic survey of the coalfields of Hyderabad commenced in July 1953.

* Central Laboratories for Scientiflc and Industrial Research, Central Laboratories for Scientific and Industrial Research, 1954.)
The Heavy Chemicals and Fertilizers Section was occupied with the utilization of felspar (including studies of bricks from felspar sludge and on the influence of silica on the recovery of potash by the calcination process) and of iron pyrites (including the preparation of manganese dithionate, manganous sulphate and sulphur), the preparation of activated charcoal from teak-wood sawdust and from groundnut hulls, and the thermal decomposition of manganese sulphate and calcium sulphate to produce sulphur dioxide. The Ceramics Section made a systematic study of Hyderabad clays and the preparation of fireclay refractories from such clays. Investigations on potential synthetic analgesics in the Organic Chemistry, Pharmaceuticals and Drugs Section covered compounds of the quinazoline type and a new synthesis of pethidine. Studies on Indian turpentine included the preparation of a chlorinated product which was highly toxic to various insect tests, and work on the synthesis of menthol. In the work on compounds with œstrogenic activity, stilbene com. pounds were obtained by condensation of 3-chlorobutanone with phenol or its ethers in presence of sulphuric acid or anhydrous aluminium chloride, but the reaction is not general for $\alpha$-halogeno ketones. 'The synthesis of 'Vanitrope' (2-ethoxy-5-propenylphenol) is being attempted and also the preparation of fine chemicals from fusel oil, while a series of ketones obtained by condensing lævulinic acid with aromatic aldehydes are being examined as plant growth regulators.

The Biochemistry Section has given its attention chiefly to the fermentation of pre-treated molasses to citric acid, to itaconic acid fermentation, to oxidations by Pseudomonas fluorescens and to the nitrogenous constituents of the seed cake of Annona squamosa. In the X-ray Section, X-ray studies were made of Hyderabad and Indian clays, while the Physical Chemistry Section investigated the conductivity of sulphuric acid in aqueous acetone and ethyl alcohol and the titration of tartaric acid with potassium dichromate. Besides the erection of the 25-ton/day low-temperature carbonization pilot plant, the Chemical Engineering Section completed work on the saturation solubilities of groundnut oil and cottonseed oil in aqueous ethyl alcohol and was further equipped with pilot-plant items for cottonseed processing, vacuum distillation and the manufacture of synthetic resins.

\section{IMPERIAL COLLEGE OF SCIENCE AND TECHNOLOGY, LONDON}

\section{REPORT FOR 1953-54}

$T$ HE forty-seventh annual report of the governing body of the Imperial College of Science and Technology, London, covering the year ended July $31,1954^{*}$, gives some details of the immediate proposals for expansion. Licences have already been granted for the erection of an additional story over the Goldsmiths' Company's extension to the City and Guilds College and the Royal School of Mines building, the first part of the extension of the chemical engineering building and the addition of two stories to the Union building. In January this

* Imperial College of Science and Technology. Forty-seventh Annual Report of the Governing Body, 1953-1954. Pp. 65. (London: Imperial College of Science and Technology, 1955.) 
year it was hoped to start the new joint building for aeronautics and for the further expansion of chemical engineering.

The academic plan envisages a much greater rate of increase in the engineering faculty than in the science faculty, with a postgraduate increase of about 160 per cent and an undergraduate increase of about 44 per cent. It is hoped to provide eventually for about fifteen hundred undergraduate and fifteen hundred postgraduate students, with perhaps half of the latter engaged in research. With the aid of a modest increase in the recurrent grant for 1954-55 and the income from the American Counterpart Funds, it is hoped that the University of London will be able in the near future to appoint professors of applied science with special reference to engineering, soil mechanics, statistics, applied geophysics and heavy electrical engineering. The new chair in heavy electrical engineering and the new readership in production engineering have been financed from sums available under the government programme for the expenditure of the Counterpart Funds, and it is expected that investment of the capital sum involved will make available about $£ 8,000$ a year. The Cement Manufacturers' Association has covenanted for a second ten years to pay $£ 2,000$ a year to continue the chair of concrete technology, and some twentytwo companies are now contributing $£ 200$ a year each to the Building and Civil Engineering Contractors' Bursary Fund. A number of seven-year covenants which will produce $£ 2,300$ a year have also given a new lease of life to the Nuffield Research Group in Extraction Metallurgy, apart from the permanent income of $£ 500$ a year eventually assured from the Imperial Smelting Corporation's Fund and the further $£ 15,000$ over five years provided by the Nuffield Foundation.

The number of full-time students for the year under review was 1,727 , compared with 1,653 in 1952-53, and, of these, postgraduate students in science and in technology numbered 223 and 349 , respectively, compared with 225 and 314 in 1952-53. of the full-time students, 111 were from foreign countries, 213 from Commonwealth countries outside the British Isles and 591 from the British Isles outside a radius of thirty miles from the College. Besides details of staff changes and the statement of accounts, a list of publications in 1953-54, arranged depart. mentally, is appended to the report.

\section{A SIMPLE METHOD FOR STUDYING AND DEMONSTRATING THE ENERGY CONSUMPTION IN FLYING INSECTS}

\section{By $D_{R}$. OLAVI SOTAVALTA}

Department of Zoology, University of Turku, Finland

$\mathrm{R}^{\mathrm{s}}$ ELATIVELY little information exists about the energy consumption in insects ; what is available consists of observations on some single species of Hymenoptera, Diptera and Orthoptera only. Beutler ${ }^{1}$ gives data on sugar consumption in the honeybee, recorded on specimens in free flight in a Flugaquarium of glass. Wigglesworth ${ }^{2}$ obtained energy consumption data of Drosophila by waxing the specimen to the head of an insect pin stuck in the cork of a glass vial, and stimulating it to flight

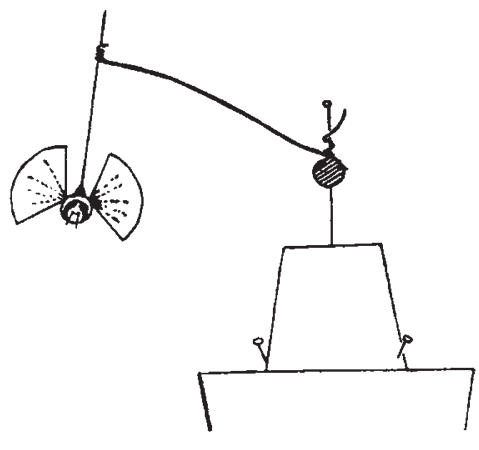

Fig. 1

by suddenly withdrawing the cork. More or less elaborate flight-mills for studying various aspects of flight of insects, including energy consumption, have been built by several authors ${ }^{3}$.

I have devised a method which was used for energy consumption studies on the honeybee, Drosophila and some other Diptera at Tufts College, Medford,

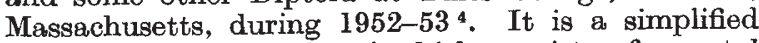
flight-mill or 'roundabout' which consists of a metal wire of suitable length, rigidity and thickness, wound loosely by one end around an insect pin, so that it can rotate easily. The pin is passed through a small ball of moulding clay to prevent the wire from falling down, and is stuck in a piece of cork (Fig. 1). The other end of the wire is wound tightly around another insect pin head down, at its point end, and the insect is, under carbon dioxide or ether anæsthesia, waxed at its thorax under a binocular microseope to the herd end of the pin. The position of the insect in respect to the three axes of space is adjusted by bending the wire and by rotating the pin within the 'tight' wire coil. In order to obtain an effective light, the insect has to face the direction of the movement, with the long axis of the body horizontal. If the body is vertical the movement may take place backwards.

Insects mounted to the instrument usually start flying when the support (a piece of paper, or a cotton ball) is removed from under the tarsi. If the insect refuses to start flying or stops by itself during flight, flight can be initiated easily by rotating the instrument backwards. As soon as a tarsus touches an object, which may be a deliberately offered support or a part of the insect's own body, the insect stops flying.

The quality of the wire and pin has naturally to conform to the size and powers of the insect. Instead of waxing to the head of a pin, small insects can be conveniently glued to the uncoiled free end of the wire with a drop of 'Duco', 'Durofix' or other suitable cement, considerably thinned with acetone.

This instrument is almost frictionless and easily rotated by the insect. Few insects except Drosophila are willing to fly stationary attached to an immovable pin according to the method of Wigglesworth ${ }^{2}$; but a considerable number fly well in this kind of roundabout. Honeybees and several other Hymenoptera are good subjects for experimenting, and flies that normally fly quietly, without sudden changes of speed, can also be used. The lesser housefly (Fannia canicularis) is an ideal subject, while the common housefly (Musca domestica) and many larger flies are less satisfactory, since they generally fly in bursts and have to be stimulated to flight incessantly. Once the flight has started, it can go on for hours until the 